\title{
Özgün araştırma makalesi Çocuklarda diş çürüğü nedeniyle birinci büyük azı dişi çekimlerinin incelenmesi
}

\author{
Müge Tokuç (iD) , ${ }^{1}$ Merve Çelik ${ }^{2}$ \\ ${ }^{1}$ Pedodonti Anabilim Dalı, Diş Hekimliği Fakültesi, İstanbul \\ Okan Üniversitesi, İstanbul, ${ }^{2}$ Diş hekimi, Özel Muayenehane, \\ Antalya, Türkiye
}

\section{Özet}

AMAÇ: Bu çalışmanın amacı; çocuklarda çürük nedeniyle çekilen birinci büyük azı dişlerinin çekim sıklığının ve çekim öncesi tedavi görme durumunun belirlenmesidir.

Gereç VE YönTEM: Bu çalışmada 7-14 yaş arası 858 hastanın 3,432 birinci büyük azı dişi panoramik radyografiler üzerinde değerlendirildi. Dişlerin mevcut ve geriye dönük durumlarının belirlenmesinde klinik kayıtlar ve fakülte arşivinde yer alan hasta anamnez formlarından faydalanıldı. Hastaların cinsiyeti, çekilmiş veya çekim endikasyonu konulmuş birinci büyük azı dişlerinin sayısı, hangi çenede ve bölgede olduğu, çekim öncesi dişe uygulanan tedavinin varlığı veya yokluğu kaydedildi. Verilerin ikili karşılaştırmaları ki-kare testi ile değerlendirildi ve istatistiksel anlamlılık düzeyi $p<0.05$ olarak belirlendi.

BuLguLAR: Değerlendirilen 858 hastanın 58'inin (\%6.8) en az 1 birinci büyük azı dişinin çekildiği veya çürük nedeniyle çekime intiyacı olduğu tespit edildi. Kız ve erkeklerde çekilen birinci daimi büyük azı dişi sayısı arasında istatistiksel fark tespit edilmedi $(p=0.918)$. Diş çekim sıklığı \%2.1 olarak belirlendi. Cinsiyete göre alt/üst çene, sağ/sol bölge arasında diş çekim sıklığı açısından fark tespit edilmedi $(p=0.359 ; p=0.918)$. Çekilen dişlerin \%40'ının herhangi bir tedavi görmeden çekildiği tespit edildi.

Sonuç: Bu çalışmada çekilen ya da çekim ihtiyacı olan birinci büyük azı dişlerinin büyük oranda herhangi bir tedavi görmediği ortaya konmuştur. Elde edilen veriler doğrultusunda, toplumumuzda çocukların diş tedavi hizmetlerine ve koruyucu tedavilere ulaşmakta geç kaldığı görülmektedir.

Anahtar Kelimeler: Azı dişi; çocuklar; diş çekimi; diş çürükleri

Makale gönderiliş tarihi: 29 Mart 2021; Yayına kabul tarihi: 23 Mayıs 2021 *Iletişim: Dr. Müge Tokuç, İstanbul Okan Universitesi, Diş Hekimliği Fakültesi, Pedodonti Anabilim Dalı, Tuzla, İstanbul, Türkiye;

E-posta: muge.tokuc@okan.edu.tr

\begin{abstract}
Kaynak Göstermek İçin: Tokuç M, Çelik M. Çocuklarda diş çürüğü nedeniyle birinci büyük azı dişi çekimlerinin incelenmesi. Acta Odontol Turc 2022;39(1):16-20
\end{abstract}

ЕрітӧR: Mügem Aslı Ekici, Gazi Üniversitesi, Ankara, Türkiye

YAYıN HAKKI: @ 2021 Tokuç ve Çelik. Bu eserin yayın hakkı Creative Commons Attribution License ile ruhsatlandırılmıştır. Sınırsız kullanım, dağıtım ve her türlü ortamda çoğaltım, yazarlar ve kaynağın belirtilmesi kaydıyla serbesttir.

FinANSAL Destek: Bulunmamaktadır.

ÇıKAR ÇATıŞMASI: Bulunmamaktadır.

[The abstract in English is at the end of the manuscript]

\section{Giriş}

Birinci büyük azı dişleri oklüzyonun normal ve dengede olması için en önemli dişlerdir ve çiğneme fonksiyonunda oldukça önemli bir yere sahiptir. Alt ve üst birinci büyük azı dişlerinin sürmesi ve kapanışa gelmesi ile süt oklüzyon değişir ve tüm dişlerin oklüzyonunu etkileyen yeni bir ilişki kurulur. ${ }^{1} \mathrm{Bu}$ nedenle birinci büyük azı dişlerinin erken kaybı birçok problemi beraberinde getirir. Birinci büyük azı dişlerinin kaybedilmesinin yarattığı en temel problem oklüzyonun bozulmasıdır. Birinci büyük azı dişinin çekimi ile birlikte oluşan boşluğa doğru yan dişler devrilirken, üst dişler de uzar. Buna bağlı olarak bireyin çiğneme alışkanlıkları değişir, çekim yapılan bölgede alveol kemiğinde rezorpsiyon ve periodontal problemler meydana gelir. Birinci büyük azı dişlerinin kaybı ikinci ve üçüncü büyük azı dişlerinin gelişimini ve sürmesini de etkiler., ${ }^{2,3}$

Literatürde, birinci büyük azılar daimi dişler içinde en fazla diş çürüğünün görüldüğü, en sık restoratif tedavi intiyacı duyulan veya çekilen dişler olarak bildirilmiştir. ${ }^{4-6}$ Birinci büyük azı dişlerinin; ikinci süt azıları ile komşuluk yapması, oklüzal yüzeyde yer alan temizlenmesi zor derin pit ve fissürlerin varlığı ve gelişimsel hipoplazilerin görülme sıklığı gibi nedenler çürük ve çürüğe neden olan etkenlere daha fazla maruz kalmasına yol açar. ${ }^{7-9}$ Danielson ve ark. ${ }^{10}$ çekilen daimi dişlerin \%95.3'ünün birinci büyük azı dişleri olduğunu bildirmiştir. Birinci büyük azı dişlerinin çekimlerinin temel nedeni diş çürükleridir, bunun dışında ortodontik nedenler (balans ve kompensasyon çekimleri), başarısız tedaviler, hastanın sosyoekonomik durumu, 
hasta veya hekim tercihi diğer çekim nedenleri arasında sayılabilmektedir. ${ }^{11-14}$

Erken yaşta diş çekimleri ağız ve diş sağlığı alanında bilimsel ve teknolojik gelişmelere rağmen hala önemli bir halk sağlığı problemi olmaya devam etmektedir. Diş çekimleri bir toplumun ağız ve diş sağlığı ile ilgili koruyucu uygulamalar ve tedavi hizmetleri konusunda başarı ya da başarısızlığının temel göstergesidir. ${ }^{15}$ Türkiye'de birinci büyük azı dişlerinin diş çürüklerinden etkilenme oranı ve tedavi intiyaçlarının farklı popülasyonlar üzerinde değerlendirildiği epidemiyolojik çalışmalar bulunmaktadır. ${ }^{5,7,15}$ Ancak bu çalışmalarda çekilen veya çekimi gereken dişlerin çekim öncesinde tedavi görüp görmediğine dair yayınlanmış bir veri bulunmamaktadır.

$\mathrm{Bu}$ çalışmanın amacı çocuklarda çürük nedeniyle çekilen birinci büyük azı dişlerinin çekim sıklığının ve çekim öncesi tedavi görme durumunun belirlenmesidir.

Tablo 1. Birinci büyük azı dişi çekilen çekilen veya çekim endikasyonu konulan hastaların cinsiyete göre dağııımları

\begin{tabular}{lllll}
\hline Diş çekimi & Kız (\%) & Erkek (\%) & Toplam (\%) & $\mathbf{p}^{*}$ \\
\hline Var & $31(6.8)$ & $27(6.7)$ & $58(6.8)$ & \multirow{2}{*}{0.918} \\
Yok & $422(93.2)$ & $378(93.3)$ & $800(93.2)$ & \\
\hline
\end{tabular}

*ki-kare testi; istatistiksel anlamlılık düzeyi: $p<0.05$

Tablo 2. Birinci büyük azı dişi çekilen veya çekim endikasyonu konulan dişlerin cinsiyete göre sağ/sol bölge, alt/üst çene dağılımları

\begin{tabular}{lllll}
\hline & Kız (\%) & Erkek (\%) & Toplam & $\mathbf{p}^{*}$ \\
\hline Üst çene & $10(29.4)$ & $13(31.7)$ & $23(30.7)$ & \multirow{2}{*}{0.830} \\
Alt çene & $24(70.6)$ & $28(68.3)$ & $52(69.3)$ & \\
Sağ bölge & $18(52.9)$ & $16(39)$ & $34(45.3)$ & 0.359 \\
Sol bölge & $16(47.1)$ & $25(60.9)$ & $41(54.6)$ & \\
\hline
\end{tabular}

*ki-kare testi; istatistiksel anlamlılık düzeyi: $p<0.05$

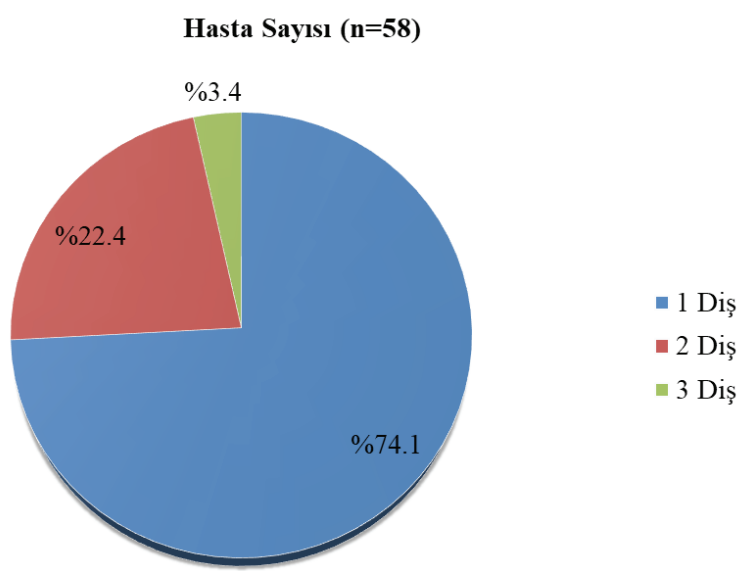

Şekil 1. Birinci büyük azı dişi çekilen veya çekim endikasyonu konulan hastaların kaybettiği diş sayısına göre dağılımı

\section{Gereç Ve Yöntem}

$\mathrm{Bu}$ retrospektif-kesitsel çalışma İstanbul Okan Üniversitesi Diş Hekimliği Fakültesi Pedodonti Anabilim Dalında gerçekleştirildi. Araştırma protokolü İstanbul Okan Üniversitesi Klinik Araştırmalar Etik Kurulu tarafından onaylandı (Protokol no:2020-24).

Çalışmaya 7-14 yaş arası, Pedodonti Anabilim Dalı Kliniğine başvuran 858 hasta dahil edildi. Kötü radyografi kalitesine sahip, diş gelişimini etkileyebilecek sistemik bir hastalığı olan, dentofasiyal anomalilere sahip (Down sendromu, dudak damak yarıkları vb.), travma veya periodontal hastalık gibi faktörlere bağlı diş çekimi yapılmış olabilecek hastalar çalışma dışı bırakıldı.

Çalışma kapsamına alınan hastaların panoramik radyografileri, klinik kayıtları ve fakülte arşivinde yer alan anamnez formaları geriye dönük olarak incelendi, hastaların yaş ve cinsiyet bilgileri kayıt edildi. Hastaların çekilmiş veya çekim endikasyonu konulmuş birinci büyük azı dişlerinin sayısı, hangi çenede ve bölgede olduğu, çekim öncesi dişe uygulanan tedavinin varlığı ve yokluğu kaydedildi.

\section{İstatistiksel analiz}

Çalışmadan elde edilen veriler IBM SPSS Statistical Software (versiyon 23; IBM, Armonk, NY, ABD) bilgisayar programı ile analiz edildi. Analiz sonuçları frekans ve yüzde olarak sunuldu. Verilerin ikili karşılaştırmaları ki-kare testi ile değerlendirildi ve istatistiksel anlamlılık düzeyi $p<0.05$ olarak belirlendi.

\section{BULGULAR}

Çalışma kapsamında değerlendirilen 858 (453 kız, 405 erkek) hastanın 58'inin (\%6.8) çürüğe bağlı olarak birinci büyük azı dişlerinden en az birinin çekildiği veya çekim intiyacı olduğu tespit edildi. Dişi çekilen veya çekim endikasyonu konulan hastaların cinsiyete göre dağılımları Tablo 1'de, kaybettiği diş sayısına göre dağılımı ise Şekil 1'de gösterilmektedir. Kız ve erkek çocuklar arasında birinci büyük azı diş çekim sıklığı açısından istatistiksel fark tespit edilmedi $(p=0.918)$ (Tablo 1). Hastaların 43'ünün (\%74.1) bir, 13'ünün (\%22.4) iki ve 2'sinin (\%3.4) ise üç birinci büyük azı dişini kaybettiği görüldü. Birinci büyük azı dişlerinin dördünü birlikte kaybeden hastaya rastlanmadı.

Değerlendirilen 858 hastada, 3,432 birinci büyük azı dişi arasından 75 (\%2.1) dişin çekildiği veya çekim intiyacı olduğu belirlendi. Dişlerin 13'ü (\%17.3) üst sağ birinci büyük azı; 10'u (\%13.3) üst sol birinci büyük azı; 31 'i (\%41.3) alt sol birinci büyük azı ve 21'i (\%28) ise alt sağ birinci büyük azı dişi olarak tespit edildi. Çekilen 75 dişin 23'ü (\%30.6) üst çenede, 52'si (\%69.3) alt çene yer almaktadır. Çekilen veya çekim endikasyonu konulan 75 dişin cinsiyete göre sağ/sol bölge, alt/ üst çene dağılımları Tablo 2'de gösterilmektedir. Kaybedilen dişlerin cinsiyete göre alt/üst çene, sağ/sol bölge dağılımları arasında istatistiksel olarak fark tespit edilmedi ( $p=0.359 ; p=0.918)$. 


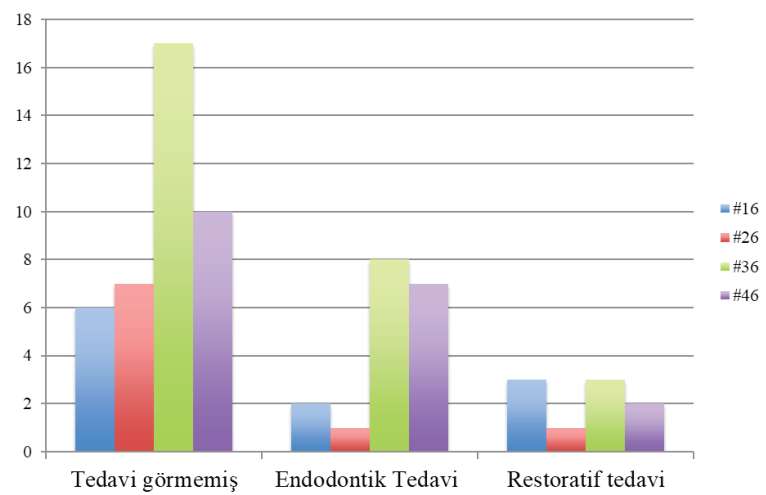

Şekil 2. Dişlerin çekim öncesi tedavi görme durumunun değerlendirilmesi (\#16: Üst sağ birinci büyük azı, \#26: Üst sol birinci büyük azı; \#36: Alt sol birinci büyük azı, \#46: Alt sağ birinci büyük azı)

Çekilmiş veya çekim endikasyonu konulmuş 75 dişin çekim öncesi yapılan tedavilere göre dağılımı Şekil 2'de gösterilmektedir. Birinci büyük azı dişlerinin \%40'ının herhangi bir tedavi görmediği, \%18'inin kök kanal tedavisi gördüğü ve \%9'unun ise restoratif tedavi gördüğü tespit edildi. Çekilen birinci büyük azı dişlerinin \%8'i ise kliniğimize gelmeden önce çekildiği ve hasta arşivinde bilgi yer almadığı için, çekim öncesi tedavi görüp görmediği öğrenilemedi.

\section{TARTIŞMA}

Epidemiyolojik çalışmalar bir ülke veya bir bölgedeki tedavi hizmetlerinin planlanması ve koruyucu hizmetlerin geliştirilmesinde intiyaç ve önceliklerin saptanması için gerekli veriyi sağlar. ${ }^{16}$ Çocuklara yönelik ağız ve diş sağlığı hizmetlerinin planlanmasında birinci büyük azı dişlerinin sağlık durumlarının belirlenmesi ayrı bir öneme sahiptir. Erken yaşta birinci büyük azı dişlerinde çürük görülen ve buna bağlı olarak erken diş kayıpları yaşayan çocuklarda meydana gelen dişsel ve gelişimsel problemler genç erişkin ve yetişkinlik döneminde de devam etmekte, komplike ve masraflı diş tedavilerine duyulan intiyacı arttırmaktadır. ${ }^{17} \mathrm{Bu}$ çalışma 7-14 yaş arası çocuklarda birinci büyük azı dişlerinin kaybedilme oranını belirleyen ve çekim öncesi tedavi görme durumları üzerine bilgi sağlayan kesitsel bir araştırmadır. Dişlerin klinik durumlarının belirlenmesi amacıyla yapılan benzer çalışmalarda hastaların panoramik röntgenlerinin incelendiği görülmüştür. . $^{3,6,7}$ Bu çalışmada da 858 hastanın klinisyen tarafından klinik olarak muayene edilmesine göre kolaylık sağladığı için hastaların panoramik röntgenlerinin incelenmesi tercih edilmiş ve buna ek olarak dişlerin mevcut ve geriye dönük durumları belirlenirken klinik kayıtlardan ve fakülte arşivinde yer alan anamnez formlarından faydalanılmıştır.

Bu çalışmanın yapıldığı hastanenin İstanbul ilinde her iki yakada da hastanesi olup, farklı sosyoekonomik yapıdaki hastaları tedavi etmektedir. Kliniklerimizde 7-14 yaş arası çocukların muayene ve tedavileri uzman çocuk diş hekimleri tarafından yapılmakta ve birinci büyük azı diş çekimlerine gerektiğinde ortodonti konsültasyonu ile birlikte karar verilmektedir. Birinci büyük azı dişlerine, aşırı kuron harabiyeti nedeniyle dişin daimi restorasyona olanak vermemesi ve hasta velisinin diş çekimini tercih etmesi durumlarında çekim endikasyonu konulmaktadır.

Sunulan çalışmada 7-14 yaş arası çocuklarda birinci büyük azı dişini kaybeden hasta oranı \%6.7 olarak tespit edilmiştir. Hastaların \%74'ünün bir, \%22'sinin iki, \%4'ünün ise üç dişini çürüğe bağlı olarak kaybettiği görülmüş ve dört dişini birlikte kaybeden hastaya rastlanmamıştır. Benzer şekilde Ozmen ve ark. ${ }^{6}$ 7-17 yaş arası 1024 hastanın 97'sinde (\%2.66), birinci büyük azı dişinin çekildiğini; 70 (\%72.1) hastanın bir, 23 (\%23.7) hastanın iki, ve 4 (\%4.1) hastanın da üç dişini birden kaybettiğini bildirmiş, dört büyük azı dişini kaybeden hastaya rastlamamışlardır. Başka bir çalışmada 12-18 yaş arası 773 hastanın 69 (\%89.2)'unun birinci büyük azı dişinin çekildiği; 41 (\%59.4) hastanın bir, 22 (\%31.8) hastanın iki ve $5(\% 7.2)$ hastanın da üç dişini birden kaybettiği tespit edilmiştir. Hastalardan sadece 1'inde dört büyük azı dişinin birlikte çekildiği görülmüştür. ${ }^{5}$ Diş çürüklerine bağlı olarak dört birinci büyük azı dişinin birlikte kaybedilmesi nadir olarak görülmektedir. Dört dişin birlikte çekiminin ortodontik nedenlerle, sıklıkla balans ve kompansasyon çekimleri nedeniyle görüldüğü bildirilmektedir. ${ }^{18}$

Çocuk ve genç yetişkinlerde daimi diş çekimleri, incelenen ülke ve popülasyonlara göre farklılık göstermektedir. Alves ve ark. ${ }^{19}$ Brezilya'da, 12 yaş grubu çocuklarda diş çürüğüne bağlı diş çekim sıklığını \%5.81 olarak tespit etmiştir. George ve ark. ${ }^{20}$ Hindistan'da, birinci büyük azı dişi çekim sıklığını 6 yaşında $\% 5.7$, 12 yaşında \%22 ve 15 yaşında \%28; Atieh ve ark. ${ }^{21}$ ise Suudi Arabistan'da 14-19 yaş grubunda \%40.9 olarak bildirmektedir. Bu çalışmada 7-14 yaş arası çocuklar sadece birinci büyük azı dişi çekim sıklığı açısından değerlendirilmiş ve oran \%2.1 olarak tespit edilmiştir. Türk popülasyonunda yapılan çalışmalara bakıldığında birinci büyük azı diş çekim sıklığının 7-17 yaş grubunda \%2.66; 6-16 yaş grubunda \%6.19; $12-18$ yaş grubunda ise \%3.4 olarak bildirildiği görülmektedir.,6,15 Duman ve ark. $^{7}$ da 5-18 yaş arası 1,449 hasta ve 5,996 diş üzerinde yaptıkları incelemede birinci büyük azı dişlerinin \%3.5'inin çekim intiyacı olduğunu, \%3.1'inin ise çekilmiş olduğunu tespit etmiştir. Toplumlar ve popülasyonlar arasında görülen bu farklılıkların her ülkenin kendine özgü sağlık sistemleri, incelenen popülasyonun sosyoekonomik durumu, diş tedavilerine ve koruyucu ağız ve diş sağlığı hizmetlerine ulaşabilme imkanı gibi farklılıklardan kaynaklandığı düşünülebilir. Aynı zamanda hekime özgü çekim endikasyonu koyma durumları ve hastaların sosyoekonomik durumu da incelenen popülasyonlarda farklı diş çekim sıklıklarının belirlenmesi üzerinde etkili olabilmektedir.3,11,21

Kızların erkeklere göre yüksek estetik beklentiye sahip olması nedeniyle dental tedavi görme oranının daha yüksek olduğu bildirilmektedir.3,6,15 Ancak cinsiyetin diş çekim sıklığı üzerindeki etkisinin 
değerlendirildiği çalışmalarda farklı sonuçlara varıldığı görülmektedir. Demirbuga ve ark. ${ }^{15}$ cinsiyetin diş çekim sıklığı üzerine bir etkisi olmadığını bildirirken, George ve ark. ${ }^{20}$ kızlarda diş çekim sıklığının erkeklere göre daha yüksek olduğunu bildirmiştir. Çocuk ve genç erişkenler birinci büyük azı çekim sıklığı açısından değerlendirildiğinde ise Gjermo ve ark. ${ }^{22}$ ile Halıcıoğlu ve ark. $^{3}$ erkeklerde diş çekim sıklığını daha yüksek bulurken, Sussin ve ark. ${ }^{23}$ kızlar ve erkekler arasında fark tespit etmemişlerdir. Bu çalışmada kız ve erkekler arasında birinci büyük azı dişi çekim sıklığı açısından fark görülmemiştir. Bu sonuçlar cinsiyet ile diş çekim sıklığı arasında bir ilişki bulunamayan çalışmaları desteklemektedir.7,23

Çalışmamızda alt çene birinci büyük azı dişlerinin çekilme sıklığının \%69.3 oranıyla üst çeneye göre daha yüksek olduğu görülmüştür. Sol alt birinci büyük azı dişi ise en çok çekilen ve çekimi gereken diş olarak tespit edilmiştir. Literatürde alt birinci büyük azı dişlerinin, üst birinci büyük azı dişlerine göre diş çürüklerinden anlamlı bir şekilde daha çok etkilendiği bildirilmiştir. Bu nedenle de alt birinci büyük azıların üst birinci büyük azılara göre daha çok tedavi edildiği veya çekildiği görülmektedir. ${ }^{15,16,24} \mathrm{Bu}$ durum alt çene birinci büyük azı dişlerinin üst çeneye göre daha erken yaşta sürmesi, morfolojik yapılarının besin tutulumuna daha uygun olması ve hipomineralizasyon görülme sıklığının daha yüksek olması ile açıklanmaktadır. Ayrıca parotis bezi kanalının üst çene büyük azılar hizasına açılması, üst birinci büyük azı dişlerinin tükürüğün yıkayıcı ve tamponlayıcı etkisine daha çok maruz kalmasına ve diş çürüklerinden daha az etkilenmesine yol açmaktadır. ${ }^{6}$

Literatürde, çocuklarda çekilen daimi dişlerin sağ ve sol bölge dağılımları incelendiğinde ise dikkate değer önemli sonuçlara varılamadığı görülmektedir. Hastanın diş fırçalarken hangi elini kullandığı ve çiğneme alışkanlıkları gibi bireysel faktörler diş çürüklerinin ve çürüğe bağlı diş çekimlerinin bölgesel dağılımını etkileyen faktörler olarak bildirilmektedir. ${ }^{10}$ Örneğin diş fırçalarken sağ elini kullanan bir hastanın sol üst bölgeyi daha etkili bir şekilde fırçaladığı bilinmektedir. Benzer şekilde çiğneme alışkanlıkları da çiğnemenin daha çok yapıldığı bölgede dişler üzerindeki mekanik temizleme etkisinin daha yüksek olmasına yol açar. ${ }^{15}$ Bu çalışmada diş çekim sıklığı sol bölgede \%54.6 sağ bölgede \%45.3 olarak tespit edilmiştir. Yapılan çalışmalarda da sağ ve sol bölge diş çekim sıklığı birbirine ve sonuçlarımıza benzer oranlarda bildirilmektedir. ${ }^{7,15}$

Ailelerin birinci büyük azı dişlerinin sürme zamanları ve önemi ile ilgili yeterli bilgiye sahip olmaması bu dişlerin diş çürüklerinden etkilenme ve çekilme oranını arttırmaktadır. ${ }^{25}$ Luca ve ark. ${ }^{26} 215$ çocuğun annesine uyguladıkları anket çalışmasında, annelerin sadece \%20.93'ünün birinci büyük azı dişlerinin sürme zamanını doğru bildiğini rapor etmiştir. Ailenin çocuklarının ağız ve diş sağlığı ile ilgili bilgi düzeylerinin artması ile çocuklarının ihtiyacı olan diş tedavisini sağlamakta, koruyucu diş hekimliği uygulamalarından faydalanma oranı artmaktadır. ${ }^{9,25}$ Literatürde birinci büyük azı dişlerinin sürme zamanı ile ilgili bilgi sahibi olan ailelerin çocuklarında çürük, dolgulu ve çekilmiş büyük azı diş sayısının daha az olduğu bildirilmektedir. ${ }^{9}$ Bu çalışmada çekilen ve çekim intiyacı duyulan dişlerin büyük çoğunluğunun daha önceden herhangi bir tedavi görmediği tespit edilmiştir. Bu sonuç ülkemizde yapılan ve ailelerin çocuklarının ağız ve diş sağlığı ile ilgili yeterli bilgiye sahip olmadığını ve diş hekimi kontrollerini ihmal ettiğini bildiren çalışmaları destekler niteliktedir. ${ }^{27,28}$

Çekilen ve çekim intiyacı olan dişler gördükleri tedavileri açısından değerlendirildiğinde dişlerin \%18'inin endodontik tedavi gördüğü ancak başarısızıık nedeni ile çekildiği tespit edilmiştir ve bu oran restoratif tedavi görmüş dişlere oranla daha yüksektir. Hunter ve ark. $^{29}$ koopere olmayan çocuklar ve izolasyonu sağlamanın zor olduğu bölgelerde yapılan tedavilerin 6 yıllık sağ kalım süresi olduğunu bildirmiştir. Endodontik tedavi sırasında koltukta geçen sürenin uzun olması hastanın kooperasyonunu olumsuz yönde etkilemekte ve ideal bir izolasyon sağlamayı zorlaştırmaktadır. $\mathrm{Bu}$ durumun restoratif tedavilere göre endodontik tedavilerde daha yüksek oranda başarısızlığa yol açtığı düşünülmektedir.

\section{SonUÇ}

Çalışmadan elde edilen en önemli verilerden biri çekilen ya da çekim intiyacı olan birinci büyük azı dişlerinin büyük oranda herhangi bir tedavi görmemiş olmasıdır. $\mathrm{Bu}$ veriler toplumumuzda çocukların diş tedavi hizmetlerine ve koruyucu tedavilere ulaşmakta geç kaldığını göstermektedir. Bunun en temel nedeninin ailelerin çocuklarının ağız ve diş sağlığı konusunda yeterli bilgiye sahip olmaması ve birinci büyük azı dişlerini süt dişi zannederek bakımlarını inmal etmeleri olduğu düşülmektedir. Birinci büyük dişlerinin çekim sıklığının azaltılabilmesi için; diş hekimlerinin doğru bilgilendirme ve yönlendirmesi ile çocuklarda ebeveyn kontrolünde etkili diş fırçalamasının sağlanması, ailelere yönelik eğitici programların planlanması ve fissür örtücü uygulamalarının yaygınlaştırılması tavsiye edilmektedir.

\section{KAYNAKLAR}

1. Andrews LF. The six keys to normal occlusion. Am J Orthod 1972;62:296-309.

2. Teo TK, Ashley PF, Parekh S, Noar J. The evaluation of spontaneous space closure after the extraction of first permanent molars. Eur Arch Paediatr Dent 2013;14:207-12

3. Halicioglu K, Toptas O, Akkas I, Celikoglu M. Permanent first molar extraction in adolescents and young adults and its effect on the development of third molar. Clin Oral Investig 2014;18:1489-94.

4. Kırzıoğlu Z, Gök B. Birinci büyük azi dişi erken kaybi ve etkileriderleme. Balıkesir Sağlık Bil Derg 2014;3:41-4

5. Kılınç G, Candan Ü, Kıpçak Akkemik Ö, Evcil M, Ellıdokuz H. 12-18 Yaş grubu çocuklarda daimi birinci büyük azi dişlerin durum değerlendirilmesi: retrospektif radyografik çalışma. Atatürk Üniv Diş Hek Fak Derg 2016:26;21-8.

6. Ozmen B. Evaluation of permanent first molar tooth loss in young population from North Turkey. Balk J Dent Med 2019;23:20-3. 
7. Duman S, Duruk G. The evaluation of the clinical and radiographic records of the first molar teeth in pediatric patients. Ann Med Res 2019;26:2333-9.

8. Willmott NS, Bryan RA, Duggal MS. Molar-incisor-hypomineralisation: a literature review. Eur Arch Paediatr Dent 2008;9:172-9.

9. Jaradat T, Ghozlan M, Showeiter M, Otom A, Kana'an N. The awareness of parents of the time of eruption of first permanent molar and caries prevalence in this tooth in children in the South of Jordan. Pak Oral Dent J 2013;33:498-501.

10. Danielson OE, Chinedu AC, Oluyemisi EA, Bashiru BO, Ndubuisi OO. Frequency, causes and pattern of adult tooth extraction in a Nigerian rural health facility. Odontostomatol Trop 2011;34:5-10.

11. McCaul LK, Jenkins WM, Kay EJ. The reasons for extraction of permanent teeth in Scotland: a 15-year follow-up study. Br Dent J 2001;190:658-62

12. Dixit LP, Gurung CK, Gurung N, Joshi N. Reasons underlying the extraction of permanent teeth in patients attending Peoples Dental College and Hospital. Nepal Med Coll J 2010;12:203-6.

13. Barbato PR, Peres MA. Tooth loss and associated factors in adolescents: a Brazilian population-based oral health survey. Rev Saude Publica 2009;43:13-25.

14. Kiraz $M$, Yüksel $B N$, Sarı Ş. Daimi birinci büyük azı dişlerinin kontrollü çekimleri: derleme. Acta Odontol Turc 2018;35:56-61.

15. Demirbuga S, Tuncay $O$, Cantekin K, Cayabatmaz M, Dincer $\mathrm{AN}$, Kilinc $\mathrm{HI}$, et al. Frequency and distribution of early tooth loss and endodontic treatment needs of permanent first molars in a Turkish pediatric population. Eur J Dent 2013;7:S099-104.

16. Motta LJ, Santos JG, Alfaya TA, Guedes CC, Godoy CHL, Bussadori SK. Clinical status of permanent first molars in children aged seven to ten years in a Brazilian rural community. Braz $\mathrm{J}$ Oral Sci 2012;11:475-80.

17. Albadri S, Zaitoun H, McDonnell ST, Davidson LE. Extraction of first permanent molar teeth: results from three dental hospitals. $\mathrm{Br}$ Dent $\mathrm{J}$ 2007;203:14-8

18. Mathu-Muju KR, Kennedy DB. Loss of permanent first molars in the mixed dentition: circumstances resulting in extraction and requiring orthodontic management. Pediatr Dent 2016;38:46-53.

19. Alves LS, Susin C, Damé-Teixeira N, Maltz M. Tooth loss prevalence and risk indicators among 12-year-old schoolchildren from South Brazil. Caries Res 2014;48:347-52.

20. George B, John J, Saravanan S, Arumugham IM. Prevalence of permanent tooth loss among children and adults in a suburban area of Chennai. Indian J Dent Res 2011;22:364.

21. Atieh MA. Tooth loss among Saudi adolescents: social and behavioural risk factors. Int Dent J 2008;58:103-8.

22. Gjermo P, Beldi MI, Bellini HT, Martins CR. Study of tooth loss in an adolescent Brazilian population. Community Dent Oral Epidemiol 1983:11:371-4

23. Susin C, Haas AN, Opermann RV, Albandar JM. Tooth loss in a young population from south Brazil. J Public Health Dent 2006;66:110-5.

24. Abuaffan $\mathrm{AH}$, Hayder $\mathrm{S}$, Hussen AA, Ibrahim TA. Prevalence of dental caries of the first permanent molars among 6-14 years old Sudanese children. Indian J Dent Edu 2018;11:13-6.

25. Gurunathan D, Moses J, Arunachalam SK. Knowledge, attitude, and practice of mothers regarding oral hygiene of primary school children in Chennai, Tamil Nadu, India. Int J Clin Pediatr Dent 2018;11:338-43.
26. Luca R, Stanciu I, Ivan A, Vinereanu A. Knowledge on the first permanent molar-audit on 215 Romanian mothers. OHDMBSC 2003;2:27-32.

27. Jahandideh A, Tüloğlu N. Ebeveynlerin Ağız-Diş Sağlığındaki Koruyucu Uygulamalar Hakkındaki Bilgilerinin Değerlendirilmesi. SDÜ Sağlık Bilimleri Dergisi 2019;10:403-12.

28. Tulunoğlu Ö, Bodur $H$, Neşe A. Aile eğitim düzeyinin okul öncesi çocuklardaki ağız diş sağlığı uygulamaları üzerine etkisinin değerlendirilmesi. GÜ Dişhek Fak Derg 1999;16:27-32.

29. Hunter B. Survival of dental restorations in young patients. Community Dent Oral Epidemiol 1985;13:285-7.

\section{Evaluation of first permanent molar extractions due to caries in children}

\section{Abstract}

OвJECTIVE: The aim of this study was to determine the frequency of the first permanent molars extracted due to caries in children and their pre-extraction treatment status.

MAterials AND Method: In this study, 3,432 first permanent molars of 858 patients, aged 7-14 years, were evaluated on panoramic radiographs. Clinical records and patient anamnesis forms were used to determine the current and retrospective status of the teeth. The gender of the patients, the number of first permanent molars extracted or indicated for extraction, localization (jaw/region), the presence or absence of treatment before extraction we re recorded. Paired comparisons of the data were evaluated with the chi-square test and significance was found as $p<0.05$.

ReSULTS: Fifty-eight (6.8\%) of 858 patients (453 girls, 405 boys) had at least one first permanent molars extracted or needed extraction due to caries. There were no statistically significant difference between girls and boys in terms of the frequency of first permanent molars extraction $(p=0.918)$. Tooth extraction frequency was determined as $2.1 \%$. There were no statistically significant differences between upper/lower jaw and right/left region distributions of extracted teeth according to gender $(p=0.359$, $p=0.918$ ). Forty percent of first permanent molars did not receive any treatment before extraction.

CONCLUSION: This study revealed that the first permanent molars that are extracted or needing extraction are substantially not treated. In line with the data obtained, it is seen that children in our society are late in accessing dental services and preventive treatments.

KEYWORDS: Children; dental caries; molar; tooth extraction 